Original article

\title{
Problem-based learning in dentistry and interfiled comparison: a citation analysis study
}

\author{
Hakimeh Hazrati, Vahideh Zarea Gavgani, Morteza Ghojazadeh, Leila Vahedi
}

Tabriz University of Medical Sciences, Tabriz, Iran

Received 21 February 2016, Accepted 11 March 2016

(C) 2016, Hazrati H., Gavgani V.Z., Ghojazadeh M., Vahedi L.

(C) 2016, Russian Open Medical Journal

Abstract: Aim - This study was designed to analyze the citations of medical education to measure primarily the research trend of Problem-based learning in medical education and to compare them in the fields of dentistry with medicine, nursing and pharmacology. Material and Methods - This study was a descriptive study using scientometrics and systematic review of citations. Electronic data bases Web of Science and PubMed were searched during the 2003-2013 for related article were extracted and critically appraised based on the level of education visualize the application of Problem-based learning in dentistry and pharmacology, nursing and medicine. We analyzed data using SPSS 18. A p-value less than 0.05 were considered significant.

Results - Dentistry 64(8\%) was ranked three followed by nursing. The dentistry was ranked in the third on sharing articles of implementing Problem based Learning in education. The year 2007 was the apex of dentistry's scientific productions on Problem based learning. Among the countries, the USA was identified leading country .All of the four fields of pharmacology, medicine, nursing, dentistry Problem based learning was the most applied in lesson than other levels of education. A statistically significantly association was found between Impact Factor and the number of citations in published articles $(p<0.001, r s=0.43$ ) and geographic dispersion (according to continental distribution) and PBL applications field $(\mathrm{P}<0.001)$.

Conclusion - These findings indicate gap Problem-based learning in the fields of medical sciences and future studies need to establish differences other fields and suggest appropriate solutions to resolve the dispute.

Keywords: problem-based learning, medical sciences, dentistry, interfiled gender, association

Cite as Hazrati H, Gavgani VZ, Ghojazadeh M, Vahedi L. Problem-based learning in dentistry and interfiled comparison: a citation analysis study. Russian Open Medical Journal 2016; 5: e0302.

Correspondence to Leila Vahedi. Adress: Liver and Gastrointestinal Disease Research Centre, Tabriz University of Medical Sciences, Tabriz, Iran. Tel.: +9141042900. Fax:+4133373741. E-mail: vahedi.149@gmail.com

\section{Introduction}

Problem-based learning (PBL) is an effective student centered approach for learning [1]. PBL in medical programs is usually implemented, although it may extend to later years. Literatures were reviewed to demonstrate the methods of effective encourages and self-directed learning, critical thinking, team working, understanding rather than memorization, successfully [2]. Barrows identify the more important learning objectives as: structuring knowledge for using in clinical contexts, more student challenge, activation of prior knowledge, discovery learning, and learning in a meaningful context.

PBL involves students with clinical matters and integrates the basic sciences with clinical sciences. Students learn the lessons as real context which is effective in memorization and persistence by PBL [3-4]. Therefore, dentistry could be an appropriate host in practical fields for implementation of PBL. Based on Schmidt's idea, applying PBL in dentistry is important and has declared that it helps to structural learning and the understanding of complex matters. Data processing helps to expand students' information by questions, answers and hypothesis criticism in the peer groups of discussion [5]. In dentistry education, a scientometric study could be effective, qualitatively and quantitatively, in order to determination the field educational and scientific productions, identification dentistry educational patterns based on PBL, and the world contribution in scientific productions, as well as clearing the weak and strength points of scientific productions.

A review on the related literatures show that various studies have been done on effect of PBL in other health domains such as medicine and pharmacology, for instance Satyanarayana [6] examined India contribution in biomedical researches (3605 papers in 1990 and 3241 papers in 1994) as indexed in three databases, including Index Medicus, Excerpt Medical and Tropical Disease Bulletin. Dandona et al. [7] conducted a study on the health research output. They concluded that both the magnitude and distribution of research output were not commensurate with the disease profile and burden. Also, Gupta has investigated on India scientific contribution in world during 1999-2004 in Medicine and has categorized them from the viewpoint of diseases and body organs. This investigation showed that the India rank was the twelfth among world scientific productions about medicine. More India's scientific contributions in Medicine associated with the Cancer and Cardiovascular diseases and were introduced as highly 
cited articles according to the citation of 100 articles [8]. Kaue studied India's programs in pharmacology, toxicology and pharmaceutics from 1998 to 2007, based on several parameters, including the country annual average growth rate, sharing and ranking of global publication, and international collaboration [3].

Rotgans et al. studied the scientometric indicators of abstracts of 60 journals with the background of Medical Education between 1988 to 2010. They gathered the high cited articles, and authors and most highly cited ones and 3 during 22 years [9]. But no citation was found in literatures. So, the impacts of $\mathrm{PBL}$ were not been measured on the citations of dentistry education. The aim of this study was to review the gap of research scientometrics and citation analysis using PBL in dentistry and medical education.

The main objective of this study is to investigate the scientific productions of PBL in 4 fields of dentistry, pharmacology, medicine, and nursing around the world. It will identify most highly cited / core journals, most highly cited articles and authors in each fields, it also will find out to what extent the PBL approach was implemented in three levels of education including: curriculum development, course and or lesson of education.

\section{Material and Methods}

This study was a descriptive study using citation analysis methods.

The ethical review committee of Tabriz University of Medical Sciences (Tabriz, Iran) approved the design of present study.

\section{Search strategy}

In the first step, databases such as PubMed and ISI Web of Science were strategically searched to find studies written in English from 2008 to September 24, 2013, at University of Medical Sciences of Tabriz, Iran. A search strategy was planned for each database based on title and abstract of articles using Boolean research methods, field, cut documentation, collection, and English language limits with keywords such as "Problem Based Learning" and "dentistry, pharmacology, medicine, and nursing by Medical Subject Headings (MeSH) for Medical Science Databases with cooperating of, PhD librarian, physiologist, PhD by Researchers, and clinical librarian. Search strategy was employed similar with the following strategy designed to PubMed:

(l(()(Problem Based Learning [Title/Abstract]) AND Medical Education [Title/Abstract]) OR Pharmacology Education) AND Problem Based Learning) OR [Nursing Education) AND Problem Based Learning) OR Dentistry Education) AND Problem Based Learning.

Finally, references were surveyed for accessibility to other related studies. Ethical aspects were considered all of stages.

\section{Evaluation and selection of studies}

In the second step, all collected studies were separately reviewed by two authors to evaluate article quality; and irrelevant and duplicated studies were excluded with appraisals' agreement. Then we asked an independent author to survey the papers in question. Finally, Kappa Agreement Rate was higher than $85 \%$ as inclusion criteria to the next stage.

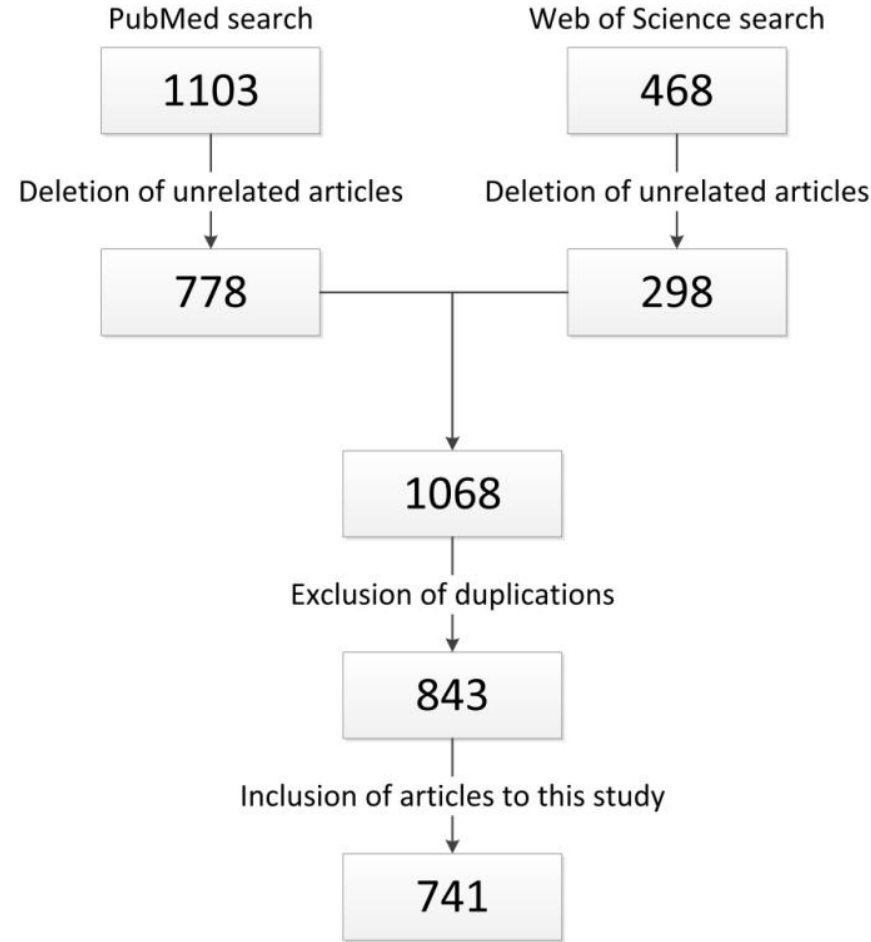

Figure 1. Workflow of selection of studies for this review

\section{Inclusion and exclusion criteria}

In the third step, irrelevant studies, without location, systematic articles, cohort articles, clinical trial articles Kappa Agreement Rate less than $85 \%$, duplication articles and letters were considered as exclusion criteria. Also, the related articles obtained manually from references of review articles were added to the set.

\section{Data extraction and statistical analysis}

Each author independently extracted data on the checklist such as the rate of published articles, highly cited / core journals, most highly cited articles and authors in four fields and levels of education (curriculum, course and lesson plan). Descriptive statistics such as mean, standard division, range, frequency, percentage, and ratio; and one way ANOVA were performed using SPSS. 18. A p-value less than 0.05 was considered significant.

\section{Results}

From two databases (Pub Med and ISI) 741 articles were found eligible to study that are shown in Figure 1.

Of 741 articles, the biggest portion of articles on PBL in medical education $533(71 \%)$ articles were published in medicine field, $54(7 \%)$ in pharmacology field, $64(8 \%)$ in dentistry field and $106(14.3 \%)$ in nursing field.

The comparison of trend of scientific productions in 4 fields, shows medicine and dentistry field, had a rising trend from 2003 to 2007, drop down until 2011 and a rising until 2013 with a sharp rise in 2013 and 2007; and a sharp drop in 2013 and 2010, respectively. 
Table1. Distribution of PBL articles in the different continents in the world

\begin{tabular}{lcccccc}
\multicolumn{1}{c}{ Tabield } & America & Europe & Asia & Africa & Australia & Total \\
\hline Medical & $173(32.9)$ & $135(25.6)$ & $136(26.0)$ & $37(7.0)$ & $45(8.5)$ & $526(71.0)$ \\
Nursing & $37(35.9)$ & $30(29.1)$ & $23(22.3)$ & $8(7.8)$ & $6(4.9)$ & $104(14.0)$ \\
Dentistry & $23(39.2)$ & $16(26.5)$ & $15(25.0)$ & 0 & $5(9.3)$ & $5<(8.0)$ \\
Pharmacology & $24(48.0)$ & $6(12.0)$ & $13(25.0)$ & $4(7)$ & $5(8.0)$ & $52(7.0)$ \\
\hline
\end{tabular}

Data presented as frequency and percentage - no. (\%).

Table 2. Core journals of PBL in the fields of medicine, pharmacology, nursing and dentistry

\begin{tabular}{|c|c|c|c|}
\hline No. & Journal & IF & Number of article (\%) \\
\hline \multicolumn{4}{|c|}{ Medicine } \\
\hline 1 & Med Educ & 2.63 & 78 (14.9) \\
\hline 2 & Med Teach & 1.49 & $77(14.8)$ \\
\hline 3 & Adv Health Sci Educ Theory Pract & 2.09 & $29(5.6)$ \\
\hline 4 & BMC Med Educ & 1.41 & $20(3.8)$ \\
\hline 5 & Academic Medical & 3.29 & $18(3.4)$ \\
\hline 6 & Educ Health (Abingdon) & 0 & $16(3.1)$ \\
\hline 7 & Kaohsiung J Med Sci & 0.5 & $12(2.3)$ \\
\hline 8 & Adv Physiol Educ & 1.55 & $12(2.3)$ \\
\hline 9 & Teach Learn Med & 0.94 & $11(2.1)$ \\
\hline 10 & Adv Health Sci Educ & 1.54 & $7(1.3)$ \\
\hline \multicolumn{4}{|c|}{ Pharmacology } \\
\hline 1 & Am J Pharm Educ & 1.21 & $23(33.3)$ \\
\hline 2 & Acta Pharmacologica Sinica & 1.68 & $3(5.6)$ \\
\hline 3 & Yakugaku Zasshi & 0.46 & $3(5.6)$ \\
\hline \multicolumn{4}{|c|}{ Nursing } \\
\hline 1 & Nursing Educ Today & 1.22 & $25(23.6)$ \\
\hline 2 & Nursing Educ Pract & 0 & $17(16)$ \\
\hline 3 & J Nurs Educ & 1.13 & $18(17)$ \\
\hline 4 & Nurs EducPerspect & 0 & $7(6.6)$ \\
\hline 5 & Int J Nurs Educ Scholarsh & 0 & $6(5.7)$ \\
\hline 7 & Stud Health Technol Inform & 0 & $3(2.8)$ \\
\hline 8 & Curationis & 0 & $3(2.8)$ \\
\hline \multicolumn{4}{|c|}{ Dentistry } \\
\hline 1 & J Dent Educ & 0.99 & $32(50)$ \\
\hline 2 & EurJ Dent Educ & 1.01 & $14(29.2)$ \\
\hline
\end{tabular}

$\mathrm{IF}$, impact factor.

In pharmacology field, trend of scientific productions and, a rising trend had a rising trend from 2006 to 2007, drop down from 2009 to 2010 with a sharp rise in 2009 and a sharp drop in 2012.

In nursing field had the most a rising trend from 2009 to 2011 and drop down from 2011 to 2013with a sharp rise in 2011 and a sharp drop in 2012.

Average status of citing to the articles with implementation of PBL in education of each field

The comparison of trend citing to the articles in 4 fields, shows medicine field, had a rising trend from 2005 to 2006, drop down until 2013 and a rising until 2003 with a sharp rise in 2013

In dentistry field, had a rising trend from 2003 to 2005, drop down until 2013 and a rising until 2007 with a sharp rise in 2006

In pharmacology field, had a rising trend in 2003, drop down until 2013 and a rising until 2003 with a sharp rise in 2013.

In nursing field had a rising trend between 2003-2007, drop down until 2013 and a rising until 2007 with a sharp rise in 2013.

In addition to, all the scientific productions (741 articles) were divided to according to continents, including Asia, Africa, America, Europe, Australia and Oceania (Table 1). There was a statistically significant relationship between geographic dispersion (according to continental distribution) and $\mathrm{PBL}$ applications in special thematic field $(P<0.001)$.

The core journal for PBL in the fields of dentistry, nursing, pharmacology and medicine are shown (Table 2).

The core journals for PBL in the field of medicine were Medical Education and Medical Teacher that each journal was published about (15\%). The field of pharmacology only 4 journals have produced more than 3 articles in the field, among them journal of Am J Pharm Educe was identified prolific by publishing 18 (33.3\%) out of 54 articles related to PBL in pharmacology. In the field of nursing, Nursing Educ Today, Nursing Educ Pract and I Nurse Educ are the prolific journals of Nursing on problem-based learning that have published $57 \%$ of 106 articles of PBL in nursing during last decade. In the field of dentistry, Journal of J Dent Educ was known as prolific journal by publishing most articles of PBL in dentistry education, i.e. 32 (50\%) articles. After that, journal of Eurj Dent Educ was ranked second with 14 (29.2\%) articles.

Top highly cited authors in each fields of dentistry, nursing, pharmacology and medicine in PBL are shown (Table 3).

In the medicine filed, D.F. Wood, from England with 584 citations has been recognized as highly cited person on PBL in 2003. His articles entitled "ABC of learning and teaching in Medical-problem based learning" was published in Brith Med $J$ with IF $=17.215$, that is the highest impact factor (IF) among published articles from 2003 to 2013. The second author with most citations was Dolmans that his article was published in Med Educ in 2005. The highly cited individual on PBL in pharmacology was K. Tavakol with 83 citations from America in 2003. He had published his article in Journal of Allied Health without IF. Herzig, was the second highly cited author in this field with 36 citations that has published his article in BMC Med Edu in 2003. BMC Med $E d u$ is an open access journal from the group of medical education journals. It is clear that the first two highly cited authors have published their articles in journals of general pharmacology rather than a pharm education journal.

The most highly cited article from among 106 articles on PBL in field nursing was related to the article entitled "A comparison of the effects of problem-based learning and lecturing on the development of students" critical thinking by A. Tiwari, which was published in Med Educ, one of the core journals of medical education in 2006. E.A. Farmer from Australia with his article entitled "Faculty development for problem-based learning", was the most highly cited person with 147 citations on PBL in field dentistry, which was published in Eur J Dent Educ in 2004. S.A. Azer was the second person after Farmer with 60 citations and almost $88 \%$ interval.

Collaborative coefficient among authors in 4 fields was calculated by collaborative coefficient (CC) formula and the results showed that pharmacology field had most team collaboration in articles. Dentistry and medicine fields were the second and third ranking, respectively. 
Table 3. Top ten highly cited authors in the field of Medical Sciences

\begin{tabular}{|c|c|c|c|c|c|}
\hline No. & Author & Year & Journal name & IF & $\begin{array}{c}\text { Number } \\
\text { of } \\
\text { citation }\end{array}$ \\
\hline \multicolumn{6}{|c|}{ Medicine } \\
\hline 1 & Wood DF & 2003 & British Med J & 17.22 & 584 \\
\hline 2 & Dolmans & 2005 & Med Educ & 2.64 & 439 \\
\hline 3 & McParland M & 2004 & Med Educ & 2.64 & 419 \\
\hline \multicolumn{6}{|c|}{ Pharmacology } \\
\hline 1 & Tavakol K & 2003 & J Allied Health & 0 & 83 \\
\hline 2 & Herzig S & 2003 & BMC Med Educ & 1.41 & 36 \\
\hline 3 & Novak, S & 2006 & Am J Pharm Educ & 1.21 & 33 \\
\hline \multicolumn{6}{|c|}{ Nursing } \\
\hline 1 & Tiwari A & 2006 & Med Educ & 2.64 & 217 \\
\hline 2 & Barnard, A & 2005 & J Nurs Educ & 1.13 & 103 \\
\hline 3 & Beers, GW & 2005 & J Nurs Educ & 1.13 & 74 \\
\hline \multicolumn{6}{|c|}{ Dentistry } \\
\hline 1 & Farmer EA. & 2004 & Eur J Dent Educ & 1.01 & 147 \\
\hline 2 & Susarla SM & 2004 & J Dent Educ & 0.99 & 47 \\
\hline 3 & Albino JE & 2008 & J Dent Educ & 0.99 & 47 \\
\hline
\end{tabular}

Table 4. Dispersion of PBL articles in the levels of educational lesson, course, and curriculum

\begin{tabular}{lcccccc}
\hline \multicolumn{1}{c}{ Field } & Curriculum & Course & Lesson & Total & P-value \\
\hline Medicine & $235(45.5)$ & $61(11.8)$ & $221(42.7)$ & 517 & \\
Nursing & $33(31.4)$ & $18(17.1)$ & $54(51.4)$ & 105 & \\
Dentistry & $38(59.4)$ & $7(10.9)$ & $19(2.7)$ & 64 & $\mathrm{P}<0.001$ \\
Pharmacology & $11(20.8)$ & $18(34.0)$ & $24(45.3)$ & 53 & \\
\hline
\end{tabular}

Data presented as frequency and percentage - no. (\%).

\section{Secondary outcomes}

Which the levels of education utilize the PBL comparing to others in 4 fields of Dentistry, Pharmacology, Medicine, and Nursing?

Analysis based on the levels of education showed that, every 4 fields mostly applied PBL in educational lesson. Most articles in each 3 educational levels (lesson, course, and curriculum) were related to Medicine. Dentistry has worked on curriculum more than Pharmacology and Nursing and ranked the second after Medicine in sharing scientific productions. Statistically significant relation was found between fields of education and the educational levels $(\mathrm{P}<0.001)$ (Table 4$)$.

\section{Discussion}

The aim of this study was to investigate scientometric study of the PBL method in related scientific articles using two databases of Medline and Web of Science in the fields of medicine, dentistry, pharmacology and nursing during 10 years (2003-2013). It was aimed to visualize the research articles related to problem based learning approach focusing specifically on the recognition of highly cited journals, articles and authors in each field and the rate of applying PBL in different educational levels including curriculum development, course and lesson plan in the articles. This investigation showed that from 741 articles included in the study, medicine's contribution on PBL scientific production was more than others, and followed by nursing, dentistry had been was in third rank before pharmacology. The rising trend of PBL publications in four fields showed that medicine had rising trend up to 2007; and a sharp rise in the recent years 2012-2013. It is probably that this rising trend was as a representative of internalizing PBL's effect in Medical Education.

Scientific productions in pharmacology are less than other three fields. It may be, because of its educational curriculum that is more Lecture-Base rather than Practice-Base. As R. Kaure et all. called it as an inherent problem of medical education around the world in 2014, because of being taught in a fixed time, teaching with traditional methods of didactic lectures to spread knowledge to a large group in short time which does not provide adequate prospect learn the subjects in contextual manner [10]. While, evidence shows merging lesson of pharmacology in dentistry and medicine field students lesson plans using a problem/case based learning lead to better learning $[10,11]$. So, it could be concluded that PBL will be more effective in case it is applied hybrid in lesson plans. As, G.C.H. Koh (2008) concluded a study about a systematic review that PBL had a positive effects on students' medical competencies; especially social and cognitive skills [12]. Also, PBL causes better fundamental knowledge and preparation for Board exams [13]. K. Thammasitboon et al. (2007) investigated the effect of change in subject-based educational curriculum to problembased curriculum by laboratory practical method on dentistry students and concluded that PBL has no effect on students' fundamental knowledge but there is a significant relationship between PBL and clinical/ practical skills and relationship with colleagues and patients $(P<0.05)$ and is the cause of improving critical thinking and deep learning and self-assessment and also increase team work [14].

Our study showed that all of the four fields (pharmacology, medicine, nursing, and dentistry) applied PBL more in lesson. It also showed that if the medical field, which has the widest field of health considering input and output, is put aside, dentistry has more contribution in scientific productions related to PBL in the level of curriculum development in comparison with pharmacology and nursing and would be the first rank of applying PBL in its educational curriculum after medicine (Table 4).

Other section of this study was related to measuring scientometrics such as the number of citations to published PBL articles during 2003-2013, and determining highly cited journals and authors. The results of this study showed that in dentistry, two journals of J Dent Educ and Eur J Dent Educ are the most highly cited journals related to PBL in Dentistry Education regarding both contribution in scientific productions and number of citations which is called core journal for PBL in dental education, also both of them are indexed in the both databases of Medline and ISI (Table 2).

In pharmacology, Am J Pharm Educ was the core journal in problem-based learning. In Nursing, three journals (J Nurse Educ, Nursing Educ Today, and Nursing Educ Pract) were the highly cited journals for PBL in nursing. Nursing Edu Today is an ISI and Medline indexed journal; and also is an open access journal. $J$ Nurs Educ has been indexed in Medline and ISI and Nursing Educ Practis have been indexed in Medline. All three journals have been indexed in Medline the expetion of Nursing Educ Prac, have just been indexed in Medline and the 2 others, apart from Medline, and are indexed in current content that is one of the subdomains of ISI Tompson Ruters. So, maybe was a relationship between the number of citations and journals' indexing (Table 2).

Most highly cited articles in Med Educ have been published from 2003 to 2005. So, it could be claimed that the most effective journal in Medical education and; especially in PBL is Med Educ. 
Also, Rotgans has determined three journals (Academic Medline, Medical Teacher and Medical Education) as the core journals in Medical Education [9].

The most highly cited articles of PBL in the field of Medicine were published in British Med J, which its main scope is not the medical education but it was considered in the list of medical journals with general scope. It has been ranked in the fourth among the top ten journals with high impact factor in Thompson Reuters Journal Citation Report (Appendix 1). It could be interfered that importance of scope and theme of the journal have not been respected by the authors in the medical science. Therefore, they publish their educational articles in general journals rather than specific journals. This issue is important from the scientific perspective due to the effect of citation count of a single paper in many of the citation indicators for formulation and calculation such as the IF of journal, $\mathrm{H}$-index of author and index of institutes. Of course, it may be an author, because of a journal's popularity, prefers to cite to a paper in a special journal like BMJ not just for the content's novelty (Table 2).

In pharmacology, just $33.3 \%$ out of 54 articles during 20032013 were published in pharmacology educational journals and the rest were published in other journals. This shows that there is not a direct relationship between journals' scope and articles about PBL, and the educational articles of Pharmacology are able to publish in the educational journals of pharmacology. It is necessary that more information was given about the scope and identification of journals; especially on the subject of pharmacological education because authors inform from the importance of their articles' publication in a journal with educational subject and its effect in readership and impact of the paper (Table 2).

The results of Spearman's correlation coefficient showed that there is a direct significant and statistical correlation between IF and number of citations in published articles of all fields of medicine, dentistry, pharmacology and nursing. Observation of data related to each field separately indicates that, there is relationship between IF and citation count in three fields of Medicine, Dentistry and Nursing, while this relationship was reverse in pharmacology field.

\section{Conclusion}

According to the findings of this study, and considering the relationship between publication year and the number of citations, it can be stressed that judgment about the validity and the effect of paper based on the longstanding scientometrics methods. Citation indicators is not reliable and needs a more critical thinking; especially in a newly published article with IF that depends on duration of two year waiting after publication.

Ultimately, lesson plan has been interested among the three levels of education, including curriculum development, course and lesson plane. That is implication to PBL based on by teachers' interest and experiences and not organized and designed by collage. Therefore, it is necessary that the curriculum was highlighted obtaining more scientific evidence on the influence of PBL in medical education, needs more scientific productions on level of development.

This study also suggests rigorous research studies on utilization of PBL in medical education in Iran to fill the evidence gap.

\section{Limitations}

Scientific production on medical education may be scattered in various international databases such as CINHAL, EMBASE, Psych info, Web of Science, and Medline/PubMed as well as national databases of every country and gray literatures. Also publication types may vary from an editorial, letter, book chapter, proceeding, to articles. We just selected PubMed and Web of Sciences due to limitation in access to other databases, and only articles published in journals indexed in the so called databases, this can be known as access or publication bias especially in systematic reviews and limitation for this study. Therefore more studies may be conducted to figure out the more visible depiction of scientific production in international databases.

\section{Acknowledgement}

Research for this article was supported by the Department of Medical Education, Education Development Center of Tabriz University of Medical Sciences (Tabriz, Iran).

\section{Conflict of Interest}

We decline no conflict of interest for this work.

This study has been funded by the Department of Medical Education, Education Development Center of Tabriz University of Medical Sciences (Tabriz, Iran)

\section{References}

1. Şendağ S, Odabaşı HF. Effects of an online problem based learning course on content knowledge acquisition and critical thinking skills. Computers \& Education 2009; 53(1): 132-141. (doi:10.1016/j.compedu.2009.01.008)

2. Sefton A. Problem-based learning. In: Dent J; Harden R (Eds.), A Practical Guide for Medical Teachers 3rd ed. UK: Churchill Livingstone, 2009: 174-180.

3. Kaur H, Gupta B. Indian contribution in pharmacology, toxicology \& pharmaceutics during 1998-2007: a scientometric analysis. Collnet Journal of Scientometrics and Information Management 2009; 3(1): 1 9. (doi: 10.1080/09737766.2009.10700859)

4. Barrows HS, Tamblyn RN. Problem-based learning: anrigorous to medical education. New York: Springer, 1980.

5. Graber DR, O'Neil EH, Bellack JP, Musham C, Javed T. Academic deans' perceptions of current and ideal curriculum emphases. J Dent Educ 1998; 62(11): 911-918. (PMID: 9893688)

6. Satyanarayana K. Final report of the project on National mapping of science: biomedical sciences. Information Today and Tomorrow 2001; 19(1): 17-21.

7. Dandona L, Sivan YS, Jyothi MN, Bhasker VS, Dandona R. The lack of public health research output from India. BMC Public Health 2004; 4 : 55. (doi: 10.1186/1471-2458-4-55) (PMID: 15563377)

8. Gupta B, Bala A. A scientometric analysis of Indian research output in medicine during 1999-2008. J Nat Sci Biol Med 2011; 2(1): 87-100. (doi: 10.4103/0976-9668.82313)

9. Rotgans JI. The themes, institutions, and people of medical education research 1988-2010: content analysis of abstracts from six journals. Adv Health Sci Educ 2012; 17(4): 515-527. (doi: 10.1007/s10459-0119328-x) (PMID: 21971993)

10. Kaur R, Kumar R, Sharma V. Case based learning as an innovative teaching tool. Int J Basic Clin Pharmacol 2014; 3(2): 395-398. (doi: 10.5455/2319-2003.ijbcp20140428)

11. Woodman OL, Dodds AE, Frauman AG, Mosepele M. Teaching pharmacology to medical students in an integrated Problem-based Learning curriculum: an Australian perspective. Acta Pharmacol Sin 2004; 25(9): 1195-1203. (PMID: 15339397) 
12. Koh GCH, Khoo HE, Wong ML, Koh D. The effects of problem-based learning during medical school on physician competency: a systematic review. Can Med Assoc J 2008; 178(1): 34-41. (doi: 10.1503/cmaj.070565) (PMID: 18166729)

13. Gregg SC, Eisenberg D, Duffy AJ, Longo WE. Design, management, and critical evaluation of a surgical basic/clinical science curriculum: The role of an educational chief resident. J Surg Educ 2008; 65(1): 36-42. (doi: 10.1016/j.jsurg.2007.09.001) (PMID: 18308279)

14. Thammasitboon K, Sukotjo C, Howell H, Karimbux N. Problem-based learning at the Harvard school of dental medicine: self-assessment of performance in postdoctoral training. J Dent Educ 2007; 71(8): 10801089. (PMID: 17687090)

Authors:

Hakimeh Hazrati - MS Medical Education, Cordinator, Medical Education Research Center, Education Development Center (EDC), Tabriz University of Medical Sciences, Tabriz, Iran.

Vahideh Zarea Gavgani - PhD, Associate Professor of Medical Library

\&Information Science, Health Services Management Research Center, National Public Health Management Center (NPMC), Tabriz University of Medical Sciences, Tabriz, Iran.

Morteza Ghojazadeh - MD,PhD, Associate Professor of Physiology, Liver \& Gastrointestinal Disease Research Center, Tabriz University of Medical Sciences, Tabriz, Iran.

Leila Vahedi - MD, PhD (Pediatric Genetic), Cordinator, Liver and Gastrointestinal Disease Research Centre, Tabriz University of Medical Sciences, Tabriz, Iran. 
Appendix 1. General Medicine Journal's Ranks in Journal Citation Report

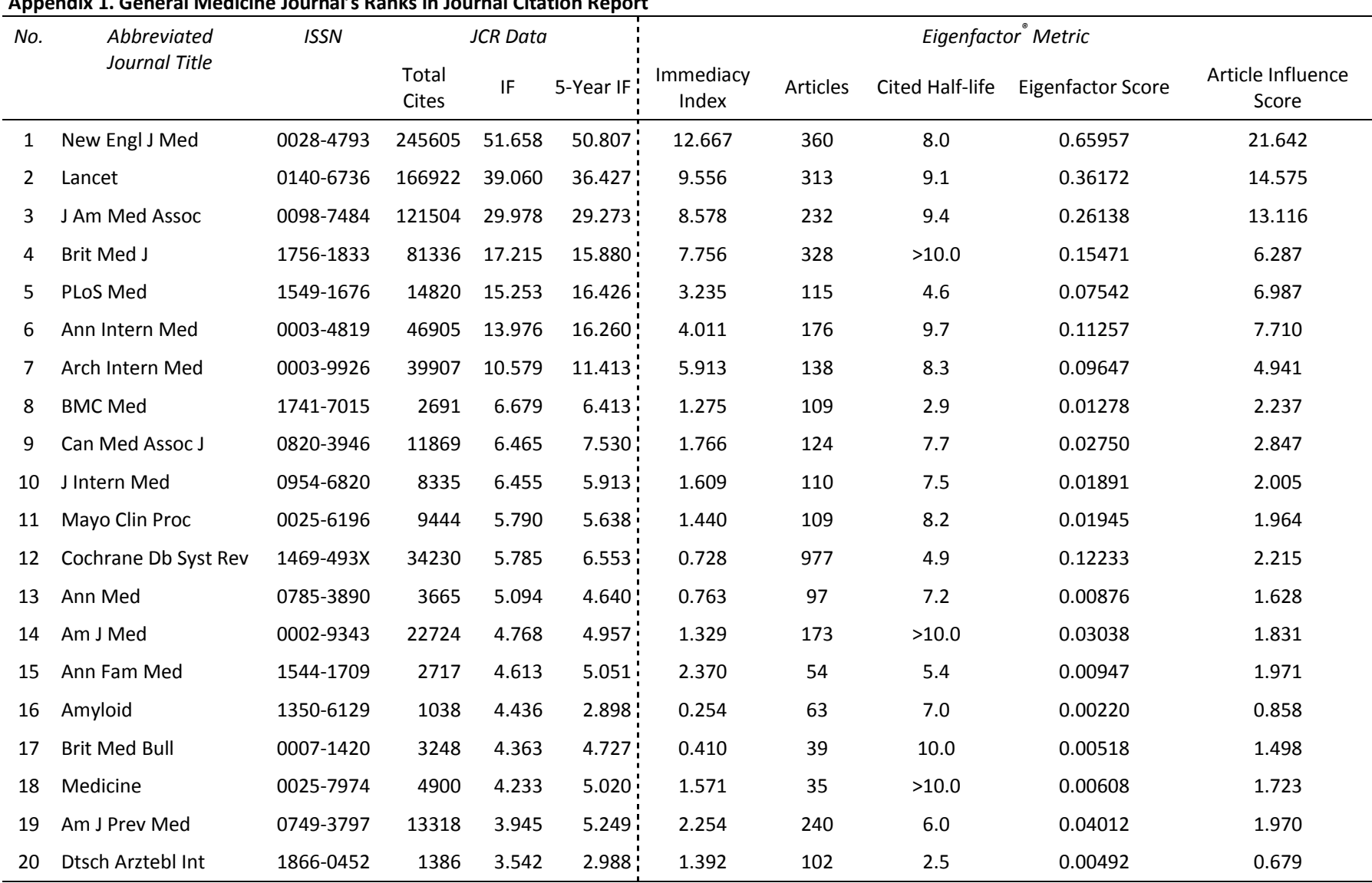

IF, impact factor. 